\title{
Effect of Adenosine on Myocardial Protection as an Adjunct to Cardioplegia during Coronary Artery Bypass Surgery
}

\author{
MD RUMMAN IDRIS , MA QUASHEM, MD KAMRUL HASAN, MD REZAUL KARIM \\ Department of Cardiac Surgery, National Institute of Cardiovascular Disease (NICVD), Dhaka \\ Address of Correspondence: Dr. Md. Rumman Idris, Assistant Registrar, Department of Cardiac Surgery, NICVD. \\ E-mail:profkamrulcts@gmail.com
}

\begin{abstract}
:
Background: Adenosine (ADO) has been known to have beneficial effects against tissue injury after myocardial ischemia. So, this study was carried out to investigate the cardio protective effect of exogenous ADO pretreatment as an adjunct to cold blood cardioplegia during coronary artery bypass surgery. Materials and methods: 50 patients (25 in each group) with coronary artery disease undergoing CABG were randomly assigned to both groups: Group A received regular institutional high-potassium ([K+] 20 mol/ 1) cold (12 ${ }^{\circ}$ C) blood cardioplegia and Group B received $250 \mathrm{ug} / \mathrm{kg}$ adenosine pretreatment followed by antegrade high-potassium cold $\left(12^{\circ} \mathrm{C}\right)$ blood cardioplegia after clamp-on. Clinical outcomes were observed before, during and after the operation. Results: There was no difference regarding operative parameters in two groups. Time to arrest was significantly shorter in group B compared to Group A, indicating that adenosine has the potential to enhance the efficacy of cardioplegic arrest. Plasma level markers of myocardial damage: cardiac Troponin I (cTnl) obtained from serial venous blood samples were significantly lower in group B during cTnl at 10 min after declamping of cross clamp and 12 hours post-operative period than group $A$. There was significantly decreased requirement of inotrope in group B during 1 st 24 hrs. Other postoperative outcomes (mechanical ventilation, ICU stay, postoperative arrhythmia and in hospital mortality were similar in both groups. Conclusion: Decreased level of cardiac enzymes and lower inotropic requirement suggests that a optimal myocardial protection with less cellular damage is obtained with adenosine pretreatment as adjunct to cold blood cardioplegia.
\end{abstract}

Keywrds: Adenosre, Myocardial Proicetion.

University Heart Journal 2018; 14(1): 21-23

\section{Introduction:}

Myocardial protection strategies play a pivotal role to protect the heart during CPB. Despite the modern cardioprotective techniques of cardiopulmonary bypass (CPB), postoperative cardiac dysfunction is a common cause of mortality and morbidity associated with CABG surgery. The underlying reason for the impaired cardiac function following $\mathrm{CPB}$ and cardioplegic arrest may be due to continued myocardial fibrillation after aortic cross-clamping that results in rapid exhaustion of myocardial ATP stores, with resulting anaerobic metabolism, acidosis, myocardial ischemia, edema, and myocardial dysfunction results in ischemic cell death. However, significant portion of the damage occurs also during the reperfusion period. This has been termed as "ischemic-reperfusion injury" (IRI), and is probably responsible for the prolonged cardiac dysfunction or "myocardial stunning" after the termination of CPB, which manifest postoperatively as depressed myocardial performances (e.g., low cardiac output), requiring inotropic or mechanical support to maintain acceptable hemodynamics. So, rapid cardiac arrest remains the mainstay of adequate myocardial protection as it minimizes the depletion of high-energy phosphate moieties by useless mechanical work during cardiac surgery. The cardio protective agent to be considered is Adenosine that could be used for achieving rapid cardiac standstill along with cardioplegia, because of its potential to enhance the efficacy of cardioplegic arrest. Clinically, adenosine pretreatment as an adjunct to blood cardioplegia, has shown to reduce IRI mediated myocardial dysfunction and also reduce the release of myocardial injury markers (Troponin I and CK-MB), indicating less myocellular injury during perioperative period.

Materials and method:

This quasi experimental study was carried out in the department of Cardiac Surgery at NICVD, Sher-E-Bangla Nagor Dhaka from July, 2012 to June 2014. A total 
number of 50 consecutive adult patients of both sexes with coronary artery disease \& recieving CABG under cardiopulmonary bypass were included in this study by purposive sampling. Patients with left main disease, EF $<30 \%$, recent MI ( $<2$ months), requiring inotropes or IABP preoperatively, emergency surgery, redo surgery, having any other surgery performed simultaneously with CABG, bronchial asthma/ chronic obstructive airway disease, 2nd \& 3rd degree heart block \& sick sinus syndrome and known prior history of hypersensitivity to adenosine were excluded. Patients were grouped into group A: Patients who received regular institutional highpotassium $([\mathrm{K}+]=20 \mathrm{~mol} / 1)$ cold $\left(12{ }^{\circ} \mathrm{C}\right)$ blood cardioplegia and Group B:

Patients who received $250 \mathrm{jag} / \mathrm{kg}$ adenosine pretreatment, followed by antegrade high-potassium cold $\left(12{ }^{\circ} \mathrm{C}\right)$ blood cardioplegia after clamp-on. Clinical outcomes were observed before, during and after the operation.

\section{Anesthesia}

All patients undergoing cardiac surgery were given general anesthesia with intubation under standard anesthetic techniques.

\section{Operative Procedure and Cardiopulmonary bypass} All patients were treated with the same CPB technique. After systemic heparinization, nonpulsatile $\mathrm{CPB}$ will be initiated using a roller pump at a flow rate of $2.4-2.6 \mathrm{~L} /$ $\mathrm{min} / \mathrm{m} 2$. Mean arterial pressure was maintained at 50 $80 \mathrm{mmHg}$ during CPB. Per operative CPB time, cross clamp time \& time required for arrest were recorded. The surgical techniques were standardized in all cases.

\section{Myocardial protection}

25 patients in the group A received regular institutional high-potassium $([\mathrm{K}+]=20 \mathrm{~mol} / 1)$ cold $\left(12{ }^{\circ} \mathrm{C}\right)$ blood cardioplegia. 25 patients in the group B received 250 fig / $\mathrm{kg}$ ADO pretreatment followed by high-potassium cold $\left(12{ }^{\circ} \mathrm{C}\right)$ blood cardioplegia after clamp-on. All patients received routine blood cardioplegia delivered through the antegrade route. The initial dose of cardioplegia was 20 $\mathrm{ml} / \mathrm{kg}$ of body weight. The two groups had cardioplegic arrest maintained by intermittent low-potassium $([\mathrm{K}+]=$ $10 \mathrm{~mol} / \mathrm{I})$ cold $\left(12{ }^{\circ} \mathrm{C}\right)$ blood institutional cardioplegia without enrichment, which was re-infused every $20 \mathrm{~min}$.

\section{Laboratory assay}

Plasma level markers of myocardial damage, cardiac Troponin I (cTnl) was obtained from serial venous blood samples after induction, $10 \mathrm{~min}$ after clamp-off, and postoperatively at 12 hour $\& 24$ hour. The concentrations of cTnl were measured by a immunoenzymometric assay by 1 MMULITE 1000 analyzer manufactured by SIEMENS, UK.

\section{Statistical analysis}

Data was processed using SPSS (Statistical Package for Social Science) version 17.0. The

statistical test was used to analyze the data are Chi-square (\%2) test and Student's t test. For all analysis a p-value $<0.05$ were considered statistically significant.

\section{Results:}

The Demographic variables in the study namely Age; Sex and anthropometric variables such as Ht. and wt. did not differ significantly between two groups. Preoperative clinical variables \& Risk factors comparison of the study found: Diabetes Mellitus and Hypertension did not differ significantly between 2 groups. Difference regarding preoperative investigations (ejection fraction \& CAG) between two groups was not statistically significant.

Per operative variables: Time of arrest in group B (11.92 \pm 3.546$)$ sec. was less than group A (28.64:^4.79) sec. And statistically result was significant $(\mathrm{p}<\mathrm{O} . \mathrm{OO})$. CPB time, ACC time and no. of grafts did not differ significantly.

Regarding the outcome variables in the study: Cardiac enzyme Troponin I level were measured between two groups during induction, 10 minutes after de clamping of aortic cross clamp, $12 \mathrm{hrs}$ postoperative \& $24 \mathrm{hrs}$ postoperatively, which revealed :During induction Troponin I level was almost identical: $0.6937 \pm 0.755$ $\mathrm{ng} / \mathrm{ml}$ vs. $0.5389 \pm 0.6956 \mathrm{ng} / \mathrm{ml}$, respectively. The difference was not statistically significant $(\mathrm{p}=0.455)$. At 10 min after de clamping of cross clamp and 12 hours post-operative period Troponin I levels between two groups were: $4.004 \pm 1.989 \mathrm{ng} / \mathrm{ml}$ vs. $2.576 \pm 1.602 \mathrm{ng} /$ $\mathrm{ml}$ and $37.219 \pm 39.084 \mathrm{ng} / \mathrm{ml}$ vs. $14.751 \pm 6.7960 \mathrm{ng} /$ $\mathrm{ml}$, respectively. In both periods, the differences were statistically significant, $p=0.007$ and $p=0.007$, respectively. At 24 hours post-operative period Troponin I level were: $13.74 \pm 9.22 \mathrm{ng} / \mathrm{ml}$ vs. $9.02 \pm 4.38 \mathrm{ng} / \mathrm{ml}$, respectively and the difference was not statistically significant $(\mathrm{p}=0.251)$. The mean $( \pm \mathrm{SD})$ dose of Dopamine (in lil $24 \mathrm{hrs)} \mathrm{between} \mathrm{group} \mathrm{A} \mathrm{and} \mathrm{group} \mathrm{B} \mathrm{were} 6.0419$ $\pm 1.61 \wedge \mathrm{gm} / \mathrm{kg} / \mathrm{min}$ and $4.7080 \pm 1.20 \mathrm{u} . \mathrm{gm} / \mathrm{kg} / \mathrm{min}$ respectively. The difference between two groups was statistically significant $(\mathrm{p}<0.05)$. Regarding postoperative variables (mechanical ventilation, ICU stay, arrhythmia and in hospital mortality) difference was not significant between 2 groups. 


\section{Discussion:}

Finding presented in the result section need further explanation to come to a conclusion. The demographic characteristics (Age and sex) and anthropometric variables such as Ht. and wt.were almost identically distributed between two groups. All co morbidities (Diabetes and hypertension) and preoperative investigations (ejection fraction \& $\mathrm{CAG}$ ) were similar in both groups. Per operative variables: Time of arrest in group B was less than group A and statistically result was significant $(\mathrm{p}<0.001)$.CPB time, ACC time and no. of grafts did not differ significantly. In the study, conducted by, ${ }^{10}$ also showed, time of arrest was significantly shorter in group $\mathrm{B}$ compared with that in group $\mathrm{A}(\mathrm{p}=0.03)$. This demonstrated that, adenosine as an adjunct to blood cardioplegia has the potential to enhance the efficacy of cardioplegic arrest Comparison of Troponin I (cTnl) values between group A and group B reveals, during induction Troponin I level were almost similar. But at 10 min. after declamping of cross clamp and 12 hours postoperative period differences of Troponin I levels between two groups were statistically significant, $\mathrm{p}=0.007$ and $p=0.007$, respectively. At 24 hours post-operative period Troponin I level were similar. In the study, conducted by ${ }^{10}$, revealed before induction, cTnl in both groups were baseline. After CPB, the levels of cTnl and CK-MB in both groups increased indicating myocardial injury. Compared with group A, group B had significantly lower $\mathrm{cTnl}(\mathrm{p}=0.03)$ at $10 \mathrm{~min}$ after aortic declamping, which was similar to our study. Other studies by ${ }^{3}$ also showed decreased level of cardiac enzymes in adenosine group, which was similar to our study. Attaining early cardiac standstill in the patients given adenosine before cardioplegia probably helped to conserve myocardial substrate. This, in turn, helped to maintain cellular integrity compared with the control group, in which the heart continued to fibrillate on cross-clamp, using up metabolic substrate and worsening myocardial ischemia. The differences of mean $( \pm$ SD) dose of Dopamine (in 1sl $24 \mathrm{hrs}$ ) between group A and group B were statistically significant $(\mathrm{p}<0.05)$. The study by, ${ }^{3}$ was consistent to our study. This suggests rapid electromechanical arrest with adenosine reduces the rate of prolonged cardiac dysfunction or "myocardial stunning" after the termination of $\mathrm{CPB}$, thus decreasing requirement of inotropic support to maintain acceptable hemodynamics. Regarding postoperative variables (mechanical ventilation, 1CU stay, arrhythmia and in hospital mortality) difference was not significant between 2 groups. Thus from the data of our study, it is evident that significant myocardial protection can be achieved by attaining rapid cardiac standstill with Adenosine.

\section{Conclusion:}

From the finding of the study and discussion thereof, it can be concluded that adenosine has the potential to enhance the efficacy of cardioplegic arrest Decreased level of cardiac enzymes and lower inotropic requirement suggests that myocardial protection with less cellular damage is obtained with adenosine pretreatment as adjunct to cold blood cardioplegia. To cold blood cardioplegia.

Further multicenter clinical trials are needed regarding adenosine pretreatment as an adjunct to cold blood cardioplegia, perhaps in high risk patients with more defined endpoints, to determine the clinical relevancy and potential benefit of adenosine pretreatment.

\section{References:}

1. Belardinelli,L., Linden, J. and Berne, R.M. The cardiac effects of adenosine. Progess in Cardiovascular Disease, 1989;32:73-97.

2. Chen, C.H., Kang, P.L., Chang, T.H., Lo, A., Ye, X.D., Lee, M. and Liu K. (2005) Bolus injection of adenosine before cardioplegic induction improves post ischemic global function in coronary artery bypass grafting. Acta Anaesthesia Taiwan, vol. 43, pp.197-204.

3. Chauhan. S., Harpreet, S. W.and Anil, B. Adenosine for Cardioplegic Induction: A Comparison with St Thomas Solution, Journal of Cardiothoracic and Vascular Anesthesia, 2000;14:21-24 Frontiers in physiology

4. Dobson, G.P., Giuseppe, F., Francesco, O. and Jakob, V.J. Hyperkalemic cardioplegia for adult and pediatric surgery: end of an era?, Frontiers in physiology, 2013;4(228):01-28.

5. Hasko, G., Linden, J., Cronstein, B. and Pacher, P. Adenosine receptors: therapeutic aspect for inflammatory and immune diseases. Nature Reviews Drug Discovery, 2008;7:759-70.

6. Lasley, R.D. and Robert, M.M. Protective Effects of Adenosine in the Reversibly Injured Heart, Annals of Thoracic Surgery, 1995;60:843-46

7. Lee, H. T., Rocco, J. I, and George, E. R. Pretreatment of Human Myocardium with Adenosine During Open Heart Surgery, Journal of Cardiac Surgery, 1995;70:665-67

8. Levitsky,S.,and McCullyJ.D. "Myocardial protection”, in F.W. Sellke , Pedro J. del N. and S. J. Swanson (ed.) Sabiston and Spencer, Surgery of The Chest. Philadelphia: Saunders, 2010; pp. 977- 98

9. Robert, M.M. Jr., Peter, S. R.and Victor, M.V. Safety, Tolerance, and Efficacy of Adenosine as an Additive to Blood Cardioplegia in Humans During Coronary Artery Bypass Surgery, American Journal of Cardiology, 1997;9:pp.

10. Ruifang, L., Jialin, X.and Na, M. The myocardial protective effect of adenosine as an adjunct to intermittent blood cardioplegia during open heart surgery, European Journal of Cardio-thoracic Surgery, 2009;36:1018-23. 